\title{
Opportunistic pathogenic fungal co-infections are prevalent in critically ill COVID-19 patients: Are they risk factors for disease severity?
}

\author{
O T Ezeokoli, PhD; C H Pohl, PhD \\ Pathogenic Yeast Research Group, Department of Microbial, Biochemical and Food Biotechnology, Faculty of Natural and Agricultural Sciences, \\ University of the Free State, Bloemfontein, South Africa
}

Corresponding author: C H Pohl (pohlch@ufs.ac.za)

Fungal co-infections, especially with Aspergillus and Candida species, are prevalent in hospitalised COVID-19 patients, and could influence patient outcomes and hamper treatment efforts. However, information about and elucidation of the causal relationship between fungal co-infections and COVID-19 disease outcomes or severity in patients are still lacking. Such information, if and when available, will help facilitate appropriate case management.

S Afr Med J 2020;110(11):1081-1085. https://doi.org/10.7196/SAMJ.2020.v110i11.15248

The novel severe-acute respiratory coronavirus 2 (SARS-CoV-2) is the cause of COVID-19, a condition that was declared a global pandemic by the World Health Organization on 30 January 2020. As of 20 August, a total of 213 countries and territories were affected by the pandemic, with $>22256219$ confirmed cases globally. ${ }^{[1]}$ The prognosis of the disease in patients with underlying conditions is dire, with comorbidities reported in a large number of hospitalised and severe cases. ${ }^{[2]}$ Based on initial reports, older individuals and individuals with pre-existing conditions such as diabetes, heart disease, chronic obstructive pulmonary disease and cancer are more predisposed than others to severe COVID-19..$^{[2,3]}$ While the mechanistic links between the aforementioned pre-existing conditions and COVID-19 severity are being unravelled, reasons for severe COVID-19 in individuals without a known history of comorbidities (otherwise healthy individuals) are somewhat puzzling and may be compounded by genetics, such as the ABO blood group, and androgens, which may predispose a person to adverse COVID19 outcomes. ${ }^{[4-6]}$ While there is much we have yet to learn about the disease, it is therefore clear that an immunocompromising condition places the patient at a disadvantage against SARS-CoV-2.

The high incidence of severe infection and mortality in COVID-19 is thought to be due in part to a lack of natural immunity and to viral replication in the lower respiratory tract, as well as superinfections, secondary infections or co-infections (these terms are often used interchangeably), leading to severe lung injury and acute respiratory distress syndrome (ARDS). ${ }^{[7]}$ Co-infections with respiratory viruses (other than SARS-CoV-2), bacteria and fungi have been reported in COVID-19 patients in Wuhan, China, ${ }^{[8-10]}$ and secondary infections were identified as one of the predictors of a fatal outcome in COVID19 cases. ${ }^{[1]}$ An earlier report from China suggests that the mortality rate for COVID-19 patients on ventilators in intensive care units (ICUs) is $\sim 60 \%$, and indicated that invasive fungal co-infections may contribute to this high mortality. ${ }^{[2]}$

Invasive fungal infections, including aspergillosis and candidiasis, ${ }^{[12-14]}$ are prevalent in hospitalised patients, and it is commonly established that acute respiratory disease, including invasive pulmonary aspergillosis (IPA), is frequent in ICUs and among immunocompromised populations. ${ }^{[15-18]}$ In addition, in some patients without a well-defined underlying immunocompromising disease, there is a high risk of secondary complications with IPA in ARDS due to viral infection. ${ }^{[19-22]}$ However, few such co-infections are being reported in the current COVID-19 pandemic, especially in South Africa (SA).

\section{Fungal co-infections are prevalent in} critically ill COVID-19 patients: Are they risk factors for severe outcomes? Fungal infections, either pre or post COVID-19 exposure, can complicate diagnosis, treatment and progression of COVID-19. ${ }^{[10,23-25]}$ At this stage, data on pre-existing fungal infections are mostly not reported. This is in part due to the likelihood of undiagnosed fungal infections in healthy individuals pre COVID-19 exposure, a lack of comprehensive descriptions of patients' clinical characteristics, and prioritisation of COVID-19 diagnosis over fungal infection diagnosis. ${ }^{[2,26-28]}$ However, a retrospective study by Gao et al. ${ }^{[29]}$ in China showed that the presence of a coexisting medical condition was the only independent risk factor for the ARDS in influenza A (H7N9) patients during the spring of 2013, with secondary bacterial or fungal infection being the cause of death in 3 out of 30 patients (10\%) who died. Shortly before the outbreak of SARS-CoV-2, Gao et al. ${ }^{[29]}$ showed that 25 of 528 patients (4.8\%) with viral pneumonia had fungal co-infections. Of these patients, 12 survived while 13 died. ${ }^{[29]}$ In addition, data from previous coronavirus outbreaks (SARS (severe acute respiratory syndrome)-CoV and MERS (Middle East respiratory syndrome)) have indicated that invasive aspergillosis and other systemic fungal infections contributed to severe outcomes for patients in ICUs. ${ }^{[1930,31]}$

With regard to secondary infections or co-infection, data from several countries show prevalence of fungal co-infections in COVID-19 patients (Table 1). From these data, it is evident that the majority of these infections are caused by Aspergillus (mostly A. fumigatus) and Candida species. These infections are not 


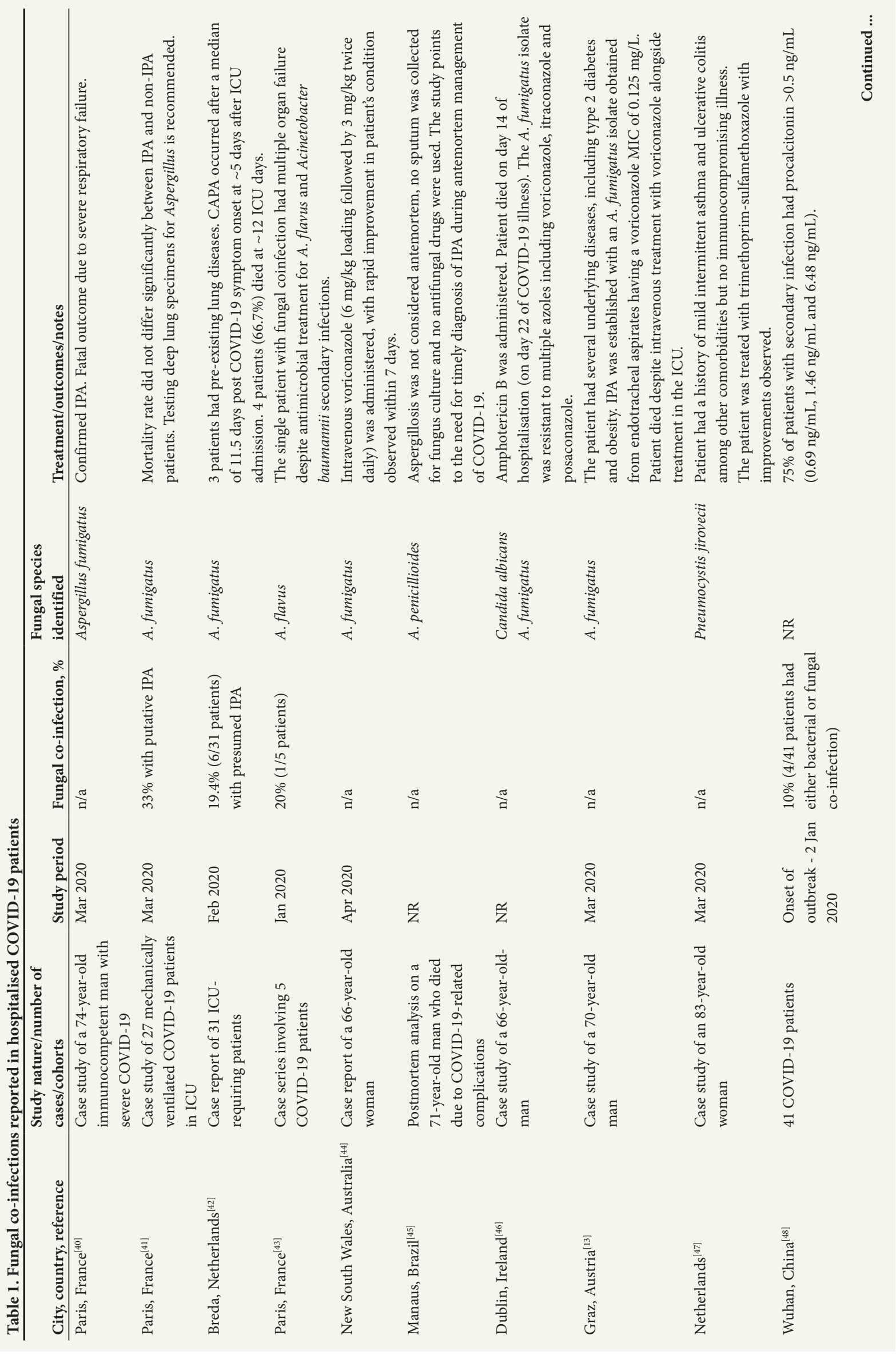




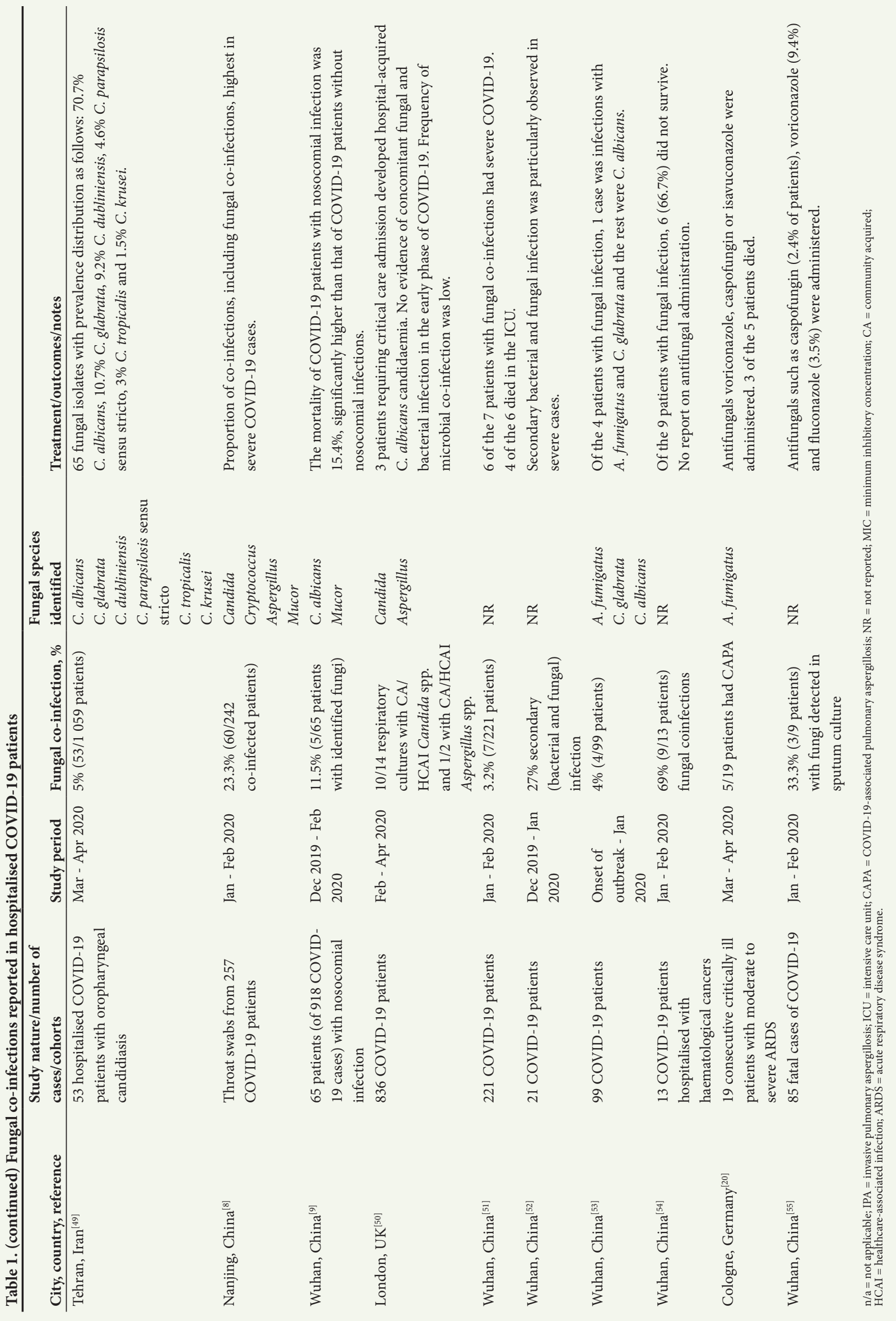


COVID-19 exclusive, but are often observed in patients admitted to ICUs. ${ }^{[32]}$ This finding complicates establishment of a causal relationship between fungal co-infection and COVID-19 disease severity, as there may be underlying conditions that predispose a patient to both infections. Interestingly, Zuo et al. ${ }^{[33]}$ reported that the gastrointestinal mycobiomes of hospitalised COVID-19 patients were more heterogeneous, more enriched for $C$. albicans and contained higher levels of C. auris and A. flavus compared with controls, even after resolution of symptoms. This finding highlights the question whether fungal colonisation contributes to or results from SARSCoV-2 infection.

\section{An SA perspective}

Studies conducted before the current COVID-19 pandemic showed that fungal infections are highly prevalent in the SA population, partly owing to the high incidence of $\mathrm{HIV}^{\left[{ }^{[34-36]}\right.}$ It was observed that the Candida carrier rate is higher in the SA population than elsewhere and that HIV-positive patients carry more and a greater variety of pathogenic yeasts compared with HIV-negative subjects. ${ }^{[35,36]}$ Similarly, cryptococcal meningitis, caused by Cryptococcus neoformans species complex, is one of the leading causes of HIV-related deaths in SA, with $>135900$ deaths estimated for sub-Saharan Africa in $2014{ }^{[34,35,37]}$ Other fungal infections, including invasive aspergillosis, Pneumocystis pneumonia and endemic mycoses, are also prevalent in SA. ${ }^{[34]}$ Given the high prevalence of HIV/AIDS in SA as well as the high number of persons undergoing immunosuppressive therapies for other illnesses, co-infections with opportunistic fungal species may be affecting the current COVID-19 disease statistics in SA. Unfortunately, information on microbial co-infections in COVID19 patients is lacking in currently published epidemiological and clinical reports on COVID-19 patients in SA. ${ }^{[38,39]}$ The extent and contribution of such fungal co-infections (either pre-existing or nosocomial) on COVID-19 patient outcomes in SA are therefore unclear. In time, meta-analyses of case reports from COVID-19 patients may help provide such answers. However, this requires that patients' histories, disease characteristics and prognosis must be well documented and accessible for meta-analyses, both globally and in SA. Such information is vital for the full appreciation of factors contributing to the current COVID-19 statistics in SA.

\section{Declaration. None.}

Acknowledgements. None.

Author contributions. OTE wrote the initial draft of the manuscript. CHP conceptualised the article, added recently published information and edited the manuscript.

Funding. The work was financially supported by the National Research Foundation (NRF). CHP holds an NRF SARChI Research Chair in Pathogenic Yeasts (grant no. 115566).

Conflicts of interest. None.

1. World Health Organization. WHO Coronavirus Disease (COVID-19) Dashboard 2020. https:// covid19.who.int/ (accessed 20 August 2020).

2. Zhou F, Yu T, Du R, et al. Clinical course and risk factors for mortality of adult inpatients with COVID-19 in Wuhan, China: A retrospective cohort study. Lancet 2020;395(10299):1054-1062. https://doi.org/10.1016/S0140-6736(20)30566-3

3. Erener S. Diabetes, infection risk and COVID-19. Mol Metab 2020;34:101044. https://doi. org/10.1016/j.molmet.2020.101044

4. Williams FM, Freydin M, Mangino M, et al. Self-reported symptoms of covid-19 including symptoms most predictive of SARS-CoV-2 infection, are heritable. MedRxiv 2020 (epub 27 April 2020). https:// most predictive of SARS-CoV-2 infection
doi.org/10.1101/2020.04.22.20072124

5. Goren A, Vaño-Galván S, Wambier CG, et al. A preliminary observation: Male pattern hair loss among hospitalized COVID-19 patients in Spain - a potential clue to the role of androgens in COVID-19 severity. J Cosmet Dermatol 2020;19(7):1545-1547. https://doi.org/10.1111/jocd.13443
6. Ellinghaus D, Degenhardt F, Bujanda L, et al. The ABO blood group locus and a chromosome 3 gene cluster associate with SARS-CoV-2 respiratory failure in an Italian-Spanish genome-wide association cluster associate with SARS-CoV-2 respiratory failure in an Italian-Spanish genome-wide
analysis. MedRxiv 2020 (epub 2 June 2020). https://doi.org/10.1101/2020.05.31.20114991

7. Kwon WJ, Zheng M, Kaur H, Magbual N, Dalai S. Superinfections and coinfections in COVID-19separating the signal from the noise. Medpage Today, 28 April 2020. https://www.medpagetoday.com/ infectiousdisease/covid19/86192 (accessed 21 June 2020).

8. Zhu X, Ge Y, Wu T, et al. Co-infection with respiratory pathogens among COVID-2019 cases. Virus Res 2020;285:198005. https://doi.org/10.1016/j.virusres.2020.198005

9. He Y, Li W, Wang Z, Chen H, Tian L, Liu D. Nosocomial infection among patients with COVID-19: A retrospective data analysis of 918 cases from a single center in Wuhan, China. Infect Control Hosp Epidemiol 2020;41(8):982-983. https://doi.org/10.1017/ice.2020.126

10. Chaung J, Chan D, Pada S, Tambyah PA. Coinfection with COVID-19 and coronavirus HKU1 - the critical need for repeat testing if clinically indicated. J Med Virol 2020;92(10):1785-1786. https://doi. org $/ 10.1002 / \mathrm{jmv} .25890$

11. Ruan Q, Yang K, Wang W, Jiang L, Song J. Clinical predictors of mortality due to COVID-19 based on an analysis of data of 150 patients from Wuhan, China. Intensive Care Med 2020;46(5):846-848. https://doi.org/10.1007/s00134-020-05991-x

12. Terraneo S, Ferrer M, Torres A. Candida spp in the respiratory tract. A real causality with worse outcomes or just a marker of severity? ICU Manage Pract 2016;16(3):158-160.

13. Pratters J, Valentin T, Hoenigl M, Reisinger AC, Eller P. Invasive pulmonary aspergillosis complicating COVID-19 in the ICU - a case report. Med Mycol Case Rep 2020 (epub 11 May 2020). https://doi. org/10.1016/j.mmcr.2020.05.001

14. Pendleton KM, Huffnagle GB, Dickson RP. The significance of Candida in the human respiratory tract: Our evolving understanding. Pathog Dis 2017;75(3):ftx029. https://doi.org/10.1093/femspd/ftx029

15. Zhou P, Liu Z, Chen Y, Xiao Y, Huang X, Fan X-G. Bacterial and fungal infections in COVID-19 patients: A matter of concern. Infect Control Hosp Epidemiol 2020;41(9):1124-1125. https://doi. org/10.1017/ice.2020.156

16. Rutsaert L, Steinfort N, van Hunsel T, et al. COVID-19-associated invasive pulmonary aspergillosis. Ann Intensive Care 2020;10(1):1-4. https://doi.org/10.1186/s13613-020-00686-4

17. Mohamed A, Rogers TR, Talento AF. COVID-19 associated invasive pulmonary aspergillosis: Diagnostic and therapeutic challenges. J Fungi 2020;6(3):115. https://doi.org/10.3390/jof6030115

18. Alp E, Voss A. Ventilator associated pneumonia and infection control. Ann Clin Microbiol Antimicrob 2006;5(1):7. https://doi.org/10.1186/1476-0711-5-7

19. Schauwvlieghe AF, Rijnders BJ, Philips N, et al. Invasive aspergillosis in patients admitted to the intensive care unit with severe influenza: A retrospective cohort study. Lancet Respir Med 2018;6(10):782-792. https://doi.org/10.1016/\$2213-2600(18)30274-1

20. Koehler P, Cornely OA, Böttiger BW, et al. COVID-19 associated pulmonary aspergillosis. Mycoses 2020;63(6):528-534. https://doi.org/10.1111/myc.13096

21. Koehler P, Bassetti M, Kochanek M, Shimabukuro-Vornhagen A, Cornely OA. Intensive care management of influenza-associated pulmonary aspergillosis. Clin Microbiol Infect 2019;25(12):15011509. https://doi.org/10.1016/j.cmi.2019.04.031

22. Buil JB, Meijer EF, Denning DW, Verweij PE, Meis JF. Burden of serious fungal infections in the Netherlands. Mycoses 2020;63(6):625-631. https://doi.org/10.1111/myc.13089

23. Kim D, Quinn J, Pinsky B, Shah NH, Brown I. Rates of co-infection between SARS-CoV-2 and other respiratory pathogens. JAMA 2020;323(20):2085-2086. https://doi.org/10.1001/jama.2020.6266

24. Gangneux J-P, Bougnoux M-E, Dannaoui E, Cornet M, Ralph ZJ. Invasive fungal diseases during COVID-19: We should be prepared. J Mycol Med 2020;30(2):100971. https://doi.org/10.1016\%2Fj. mycmed.2020.100971

25. Ding Q, Lu P, Fan Y, Xia Y, Liu M. The clinical characteristics of pneumonia patients coinfected with 2019 novel coronavirus and influenza virus in Wuhan, China. J Med Virol 2020;92(9):1549-1555. https://doi.org/10.1002/jmv.25781

26. Verweij PE, Gangneux J-P, Bassetti M, et al. Diagnosing COVID-19-associated pulmonary aspergillosis. Lancet 2020;1(2):E53-E55. https://doi.org/10.1016/S2666-5247(20)30027-6

27. NHS. Prioritisation/deferral of pathology laboratory work (in light of SARSCoV-2 (COVID19) epidemic). 2020. https://www.rcpath.org/uploads/assets/55123842-950f-49c5-bf69ed866a7ca3da/ epidemic). 2020. https://www.rcpath.org/uploads/assets/55123842-950f-49c5-bf6
Prioritisation-deferral-of-pathology-laboratory-work.pdf (accessed 18 August 2020).

28. Govender NP. Why we should take fungal infections more seriously. National Institute for Covender NP. Why we should take fungal infections more seriously. National Institute for
Communicable Diseases, 4 October 2018. https://www.nicd.ac.za/we-should-take-fungal-infectionsCommunicable Diseases, 4 October 2018. https://w
more-seriously-heres-why/ (accessed 30 June 2020).

29. Gao H-N, Lu H-Z, Cao B, et al. Clinical findings in 111 cases of influenza A (H7N9) virus infection. N Engl J Med 2013;368(24):2277-2285. https://doi.org/10.1056/NEJMoa1305584

30. Hwang DM, Chamberlain DW, Poutanen SM, Low DE, Asa SL, Butany J. Pulmonary pathology of severe acute respiratory syndrome in Toronto. Mod Pathol 2005;18(1):1-10. https://doi.org/10.1038/ modpathol. 3800247

31. Ahmadi A, Ardehali SH, Beigmohammadi MT, et al. Invasive candidiasis in intensive care unit: Consensus statement from an Iranian panel of experts, July 2013. JRSM Open 2014;5(3):1-10. https:// doi.org/10.1177/2042533313517689

32. Bassetti M, Garnacho-Montero J, Calandra T, et al. Intensive care medicine research agenda on invasive fungal infection in critically ill patients. Intensive Care Med 2017;43(9):1225-1238. https:// doi.org/10.1007/s00134-017-4731-2

33. Zuo T, Zhan H, Zhang F, et al. Alterations in fecal fungal microbiome of patients with COVID-19 during time of hospitalization until discharge. Gastroenterology 2020 (epub 26 June 2020). https://doi. org/10.1053/.gastro.2020.06.048

34. Schwartz IS, Boyles TH, Kenyon CR, Hoving JC, Brown GD, Denning DW. The estimated burden of

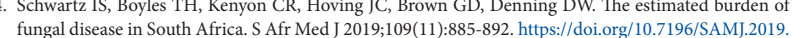
fungal disease in

35. Rajasingham R, Smith RM, Park BJ, et al. Global burden of disease of HIV-associated cryptococcal meningitis: An updated analysis. Lancet Infect Dis 2017;17(8):873-881. https://doi.org/10.1016/S14733099(17)30243-8

36. Patel M, Shackleton JT, Coogan MM. Effect of antifungal treatment on the prevalence of yeasts in HIV-infected subjects. J Med Microbiol 2006;55(9):1279-1284. https://doi.org/10.1099/jmm.0.46588-0

37. National Institute for Communicable Diseases. The impact of COVID-19 public health measures on diagnosis of advanced HIV disease, cryptococcal antigenaemia and cryptococcal meningitis in South Africa. 15 June 2020. https://www.nicd.ac.za/wp-content/uploads/2020/06/COVIDImpact_ CryptoScreening_2020-06_15-002.pdf (accessed 20 August 2020).

38. Zamparini J, Venturas J, Shaddock E, et al. Clinical characteristics of the first 100 COVID-19 patients admitted to a tertiary hospital in Johannesburg, South Africa. Wits J Clin Med 2020;2(2):105-114. https://doi.org/10.18772/26180197.2020.v2n2al

39. National Institute for Communicable Diseases. COVID-19 surveilance reports. 2020. https://www. nicd.ac.za/diseases-a-z-index/covid-19/surveillance-reports/ (accessed 20 August 2020).

40. Blaize M, Mayaux J, Nabet C, et al. Fatal invasive aspergillosis and coronavirus disease in an immunocompetent patient. Emerg Infect Dis 2020;26(7):1636-1637. https://doi.org/10.3201/ eid2607.201603

41. Alanio A, Delliere S, Fodil S, Bretagne S, Megarbane B. High prevalence of putative invasive pulmonary aspergillosis in critically ill COVID-19 patients. Lancet Respir Med 2020;8(6):e48-e49. https://doi. org/10.1016/S2213-2600(20)30237-X 
42. Van Arkel AL, Rijpstra TA, Belderbos HN, van Wijngaarden P, Verweij PE, Bentvelsen RG. COVID19-associated pulmonary aspergillosis. Am J Respir Crit Care Med 2020;202(1):132-135. https://doi org/10.1164/rccm.202004-1038LE

43. Lescure F-X, Bouadma L, Nguyen D, et al. Clinical and virological data of the first cases of COVID-19 in Europe: A case series. Lancet Infect Dis 2020;20(6):697-706. https://doi.org/10.1016/S1473in Europe: $A$ case

44. Sharma A, Hofmeyr A, Bansal A, et al. COVID-19 associated pulmonary aspergillosis (CAPA): An Australian case report. Med Mycol Case Rep 2020 (epub 18 June 2020). https://doi.org/10.1016/j. Australian case rep
mmcr.2020.06.002

45. Santana MF, Pivoto G, Alexandre MAA, et al. Confirmed invasive pulmonary aspergillosis and COVID-19: The value of postmortem findings to support antemortem management. Rev Soc Bras Med Trop 2020;53:e20200401. https:// doi.org/10.1590/0037-8682-0401-2020 Med Trop 2020,53:2020001

46. Mohamed A, Hassan T, Trzos-Grzybowska M, et al. Mult-(riazole-resistant Aspergillus fumigatus and SARS-CoV-2 co-infection: A lethal combing https://doi.org/10.1016/j.mmcr.2020.06.00

47. Menon AA, Berg DD, Brea EJ, et al. A case of COVID-19 and Pneumocystis jirovecii co-infection. Am J Respir Crit Care Med 2020;202(1):136-138. https://doi.org/10.1164/rccm.202003-0766L

48. Huang C, Wang Y, Li X, et al. Clinical features of patients infected with 2019 novel coronavirus in Wuhan, China. Lancet 2020;395(10223):497-506. https://doi.org/10.1016/S0140-6736(20)30183-5

49. Salehi M, Ahmadikia K, Mahmoudi S, et al. Oropharyngeal candidiasis in hospitalized COVID-19 patients from Iran: Species identification and antifungal susceptibility pattern. Mycoses 2020;63(8):771778. https://doi.org/10.1111/myc.13137
50. Hughes S, Troise O, Donaldson H, Mughal N, Moore LS. Bacterial and fungal coinfection among hospitalised patients with COVID-19: A retrospective cohort study in a UK secondary care setting hospitalised patients with COVID-19: A retrospective cohort study in a UK secondary
Clin Microbiol Infect 2020;26(20):1395-1399. https://doi.org/10.1016/..cmi.2020.06.025

51. Zhang G, Hu C, Luo L, et al. Clinical features and short-term outcomes of 221 patients with COVID-19 in Wuhan, China. J Clin Virol 2020;127:104364. https://doi.org/10.1016/j.jcv.2020.104364

52. Chen G, Wu D, Guo W, et al. Clinical and immunological features of severe and moderate coronaviru disease 2019. J Clin Invest 2020;130(5):2620-2629. https://doi.org/10.1172/JCI137244

53. Chen N, Zhou M, Dong X, et al. Epidemiological and clinical characteristics of 99 cases of 2019 novel coronavirus pneumonia in Wuhan, China: A descriptive study. Lancet 2020;395(10223):507-513. https://doi.org/10.1016/S0140-6736(20)30211-7

54. He W, Chen L, Chen L, et al. COVID-19 in persons with haematological cancers. Leukemia 2020;34:1637-1645. https://doi.org/10.1038/s41375-020-0836-7

55. Du Y, Tu L, Zhu P, et al. Clinical features of 85 fatal cases of COVID-19 from Wuhan: A retrospective observational study. Am J Respir Crit Care Med 2020;201(11):1372-1379. https://doi.org/10.1164/ rccm.202003-05430C

Accepted 27 September 2020. 